\title{
Airborne Single Particle Mass Spectrometers (SPLAT II \& miniSPLAT) and New Software for Data Visualization and Analysis in a Geo-Spatial Context
}

\author{
Alla Zelenyuk, ${ }^{1}$ Dan Imre, ${ }^{2}$ Jacqueline Wilson, ${ }^{1}$ Zhiyuan Zhang, ${ }^{3}$ Jun Wang, ${ }^{3}$ Klaus Mueller ${ }^{3}$ \\ ${ }^{1}$ Pacific Northwest National Laboratory, Richland, WA 99354, USA \\ ${ }^{2}$ Imre Consulting, Richland, WA 99352, USA \\ ${ }^{3}$ State University of New York, Stony Brook, NY 11790, USA
}

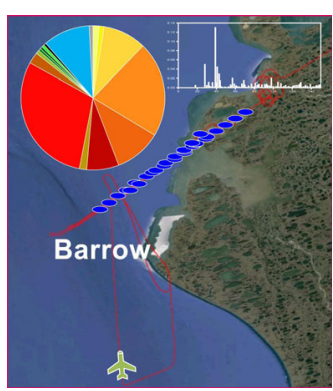

Abstract. Understanding the effect of aerosols on climate requires knowledge of the size and chemical composition of individual aerosol particles-two fundamental properties that determine an aerosol's optical properties and ability to serve as cloud condensation or ice nuclei. Here we present our aircraft-compatible single particle mass spectrometers, SPLAT II and its new, miniaturized version, miniSPLAT that measure in-situ and in real-time the size and chemical composition of individual aerosol particles with extremely high sensitivity, temporal resolution, and sizing precision on the order of a monolayer. Although miniSPLAT's size, weight, and power consumption are significantly smaller, its performance is on par with SPLAT II. Both instruments operate in dual data acquisition mode to measure, in addition to single particle size and composition, particle number concentrations, size distributions, density, and asphericity with high temporal resolution. We also present ND-Scope, our newly developed interactive visual analytics software package. ND-Scope is designed to explore and visualize the vast amount of complex, multidimensional data acquired by our single particle mass spectrometers, along with other aerosol and cloud characterization instruments on-board aircraft. We demonstrate that ND-Scope makes it possible to visualize the relationships between different observables and to view the data in a geo-spatial context, using the interactive and fully coupled Google Earth and Parallel Coordinates displays. Here we illustrate the utility of ND-Scope to visualize the spatial distribution of atmospheric particles of different compositions, and explore the relationship between individual particle compositions and their activity as cloud condensation nuclei.

Keywords: Single particle mass spectrometer, Aerosol composition, Aerosol size, Cloud condensation nuclei

Received: 6 September 2014/Revised: 27 October 2014/Accepted: 31 October 2014/Published Online: 7 January 2015

\section{Introduction}

tmospheric aerosols play an important role in air quality,
visibility, and regional and global climate. Aerosols affect
the Earth's radiation balance directly by scattering and absorb-
ing solar radiation and, indirectly, by serving as cloud conden-
sation nuclei (CCN) and ice nuclei (IN), thus determining
properties of clouds [1-7]. While absorbing aerosols [i.e.,
particles containing black carbon emitted by mobile sources

Electronic supplementary material The online version of this article (doi:10.1007/s13361-014-1043-4) contains supplementary material, which is available to authorized users.

Correspondence to: Alla Zelenyuk; e-mail: alla.zelenyuk-imre@pnnl.gov and biomass burning (BB)] contribute to global warming, nonabsorbing particles, especially those that serve as $\mathrm{CCN}$ and IN, can mitigate global warming [1, 2, 4-7]. The effect aerosols have on clouds, termed indirect aerosol effect, is particularly important because clouds cover more than $50 \%$ of the Earth's surface and play a critical role in the global climate. The relationship between the properties of aerosol particles and clouds, however, remains the most uncertain aspect in our current understanding of climate change [2].

Aerosol optical properties-scattering and absorption - depend on particle number concentrations, size distributions, individual particle composition, and relative humidity (RH). Similarly, cloud formation and cloud optical properties and lifetimes are tightly connected to the properties of the particles on which they form [8]. Moreover, because the 
fraction of particles activated to form clouds is not linearly dependent on particle number concentrations, size, and composition, it is essential to know the spatial distributions of all relevant aerosol properties with relatively high resolution.

Characterization of aerosol particles represents a significant challenge: most ambient aerosol samples are comprised of complex and evolving mixtures of particles with different compositions and sizes, which determine their optical properties, CCN and IN activity. Hence, developing a fundamental understanding of the aerosol effect on climate requires knowing the sizes and chemical compositions of individual aerosol particles [9]. High instrument sensitivity and temporal resolution is needed to characterize particles with large variations in both composition and size, and this is particularly true for measurements on-board aircraft [10-12]. For example, because of lack of information on size and composition of individual particles, studies designed to investigate the relationship between cloud activation and aerosol properties most often rely on instruments that yield bulk chemical composition of the assembly of aerosol particles [13-18], which unfortunately can lead to conflicting conclusions on the effect of aerosol composition on CCN activity [19-21].

Within the past two decades, single particle mass spectrometers (SPMS) have been successfully deployed on the ground, on-board ships, and on-board aircraft to characterize, in-situ and in real-time, the size and composition of individual ambient particles and their spatial and temporal evolution (e.g., [11, 22-24] and references therein). An aircraft deployment represents the most appropriate platform for studying the atmosphere and atmospheric aerosol particles. This is particularly true for the studies of aerosol-cloud interactions that require knowledge of the properties of particles below, within, and above the cloud.

The design and deployment of aircraft instrumentation presents significant additional challenges [11,24]. Such instruments must comply with stringent requirements related to their weight, dimensions, power consumption, heat dissipation, mechanical stresses, and sensitivity to vibrations. Moreover, aircraft deployment greatly increases demands on instrument performance: high aircraft speed necessitates temporal resolution on the order of $\sim 1 \mathrm{~min}$, and because the majority of atmospheric particles are much smaller than $200 \mathrm{~nm}$ in diameter, the instruments must have high sensitivity to small particles.

Once an SPMS has been used to collect data, its analysis presents further unique challenges [25-31]. SPMS produce vast amounts of detailed multidimensional data, the visualization, classification, mining, and analysis of which call for unconventional methods that must draw on statistical methods, while preserving the wealth and depth of information in the data [25-37]. Moreover, analysis of data acquired during airborne field deployment must be done in a geo-spatial context and, for complete analysis, should include relevant data collected by all other instruments.

Several reviews and papers describe in detail the different SPMS [22, 23, 38-46], including a few that have been deployed on-board aircraft [11, 24, 47]. Here we will focus primarily on our aircraft-compatible single particle mass spectrometers, SPLAT II [11] and miniSPLAT, the new miniaturized version. Both of these instruments have the sensitivity, temporal resolution, precision, and quantitative capability to fulfill all the requirements of aircraft deployment. We will use our aircraft data to illustrate in-situ characterization of atmospheric particles using SPMS and the exploration of the vast amount of gathered data, in the geo-spatial context. The latter is accomplished using our newly developed interactive visual analytics framework, ND-Scope. ND-Scope uses the Google Earth (GE) plugin display to incorporate various visual data representations, and is tightly linked to an interactive parallel coordinates display used for visualization and analysis of large multidimensional data sets [35].

The dataset used here to demonstrate our software utility was acquired by SPLAT II deployed on-board the National Research Council of Canada Convair-580 aircraft as part of the Indirect and Semi-Direct Aerosol Campaign (ISDAC) that took place during the International Polar Year at the North Slope of Alaska [48]. More specifically this data was collected on April 20, 2008 during Flight 26 (F26). The aircraft was equipped with a suite of instruments for aerosol and cloud characterization designed to provide a detailed picture of the particle number concentrations, size distributions, concentrations of $\mathrm{CCN}$ and IN, along with cloud microphysics measurements [48]. The main scientific objective of this month-long field campaign was to improve our understanding of how changes in the size, composition, and concentration of aerosol particles influence cloud properties and their associated radiative forcing.

The Arctic region represents an interesting and important location to study the forces that affect the global climate. Arctic aerosols are commonly advected into the region from Asia, Europe, and North America, and their loadings, compositions, and all other properties vary significantly with time, location, and meteorology. It has been suggested that the recent increase in the Arctic near-surface temperature [2], which is nearly twice as large as the global average, can be related to mitigating policies that resulted in a reduction in aerosol loadings over the region [1].

\section{Experimental}

A detailed description of the design elements and performance of our larger aircraft-compatible single particle mass spectrometer, SPLAT II, is provided elsewhere [11], and here we focus on the analysis of data produced by SPLAT II during the ISDAC field campaign. We note that SPLAT II participated in all 27 campaign flights, totaling over 100 flight hours, and needed no realignment or adjustments. During the campaign, it measured the vacuum aerodynamic diameter $\left(d_{v a}\right)$ of tens of millions of particles with diameters from 50 to $2000 \mathrm{~nm}$ and characterized the composition of $\sim 3$ million particles. 
Most recently, to improve instrument suitability for small aircraft, like a Gulfstream G-1, we designed and constructed a miniaturized version of our SPLAT II, known as miniSPLAT. miniSPLAT works on the same scientific principles as SPLAT II but has been significantly reduced in size, weight, and power consumption without loss in performance. miniSPLAT fits into a double-wide, 19-in. aircraft-approved rack $(105 \times 61 \times 122 \mathrm{~cm}$ $\mathrm{W} \times \mathrm{D} \times \mathrm{H}$ ); its total mass is $225 \mathrm{~kg}$ compared with the $400 \mathrm{~kg}$ SPLAT II, and its power consumption is $920 \mathrm{~W}$ compared with $3500 \mathrm{~W}$ for SPLAT II.

A schematic and photograph of miniSPLAT is shown in Figure 1. In order to significantly reduce instrument weight, nearly all of miniSPLAT's hardware components, including its mass spectrometer, are made of aluminum. Where practical, weight was further reduced by making components hollow. miniSPLAT consists of an inlet, two differentially pumped sections, the particle detection chamber, and a dual polarity Z-configuration reflectron time-of-flight (Z-TOF) mass spectrometer [47, 49].

Aerosol particles enter an aerodynamic lens through a $100-\mu \mathrm{m}$ critical orifice at a sampling rate of $\sim 0.1 \mathrm{1} / \mathrm{min}$. Four turbomolecular pumps (Model Turbo-V 301; Varian Vacuum Technologies, Torino, Italy), one for each of the vacuum sections separated by skimmers, are backed by a single dry scroll pump (Model nXDS15i; Edwards, Sanborn, NY, USA). This pumping scheme yields an optimal pressure of $\sim 2$ Torr in front of the first orifice of the aerodynamic lens inlet and $\sim 1.5 \cdot 10^{-7}$ Torr inside the mass spectrometer. During operation on-board the aircraft, miniSPLAT is ready to operate $\sim 30 \mathrm{~min}$ after beginning instrument power up.

The aerodynamic lens inlet forms a low-divergence particle beam and transports particles into the vacuum system with extremely high efficiency [11, 50-53]. In addition, particles exit the lens with a velocity that is a narrow function of their vacuum aerodynamic diameter $\left(d_{v a}\right)$, making it possible to determine particle size with a precision of a monolayer [11, 53]. To measure individual particle size and composition, each particle is detected by light scattering at two optical detection stages spaced $10.9 \mathrm{~cm}$ apart. Particle time of flight (PTOF) between the two detection stages is used to determine particle velocity and thus $d_{v a}$. Both miniSPLAT and SPLAT II are currently equipped with the same redesigned aerodynamic lens inlet [54] that significantly improves particle beam quality and, with it, the detection efficiency of small particles. Similarly, the optical detection stages, their components [elliptical reflectors, light scattering lasers, photomultipliers (PMTs), and baffles], geometries, and signal processing electronics in the two instruments are identical [11]. miniSPLAT and SPLAT II [53] are the only SPMS that use photon counting for particle detection. The background was decreased by using high quality $300 \mathrm{~mW}$ $532 \mathrm{~nm}$ Nd:YAG lasers (CrystaLaser, Model CL-300-LO, Reno, NV, USA) with custom built-in focusing optics, high quality AR-coated windows, blackened instrument, precisely designed and constructed light baffling system, and precisely positioned orifices in front of each PMT [11]. The high inlet transmission efficiency of spherical particles with diameters between $125 \mathrm{~nm}$ and $600 \mathrm{~nm}$ [11] and the fact that their scattered light signal saturates the PMTs [55] assure their 100\% detection efficiently. The rapid decrease in detection efficiency of smaller particles reflects an increase in particle beam divergence and decrease in light scattering signal [11, 54-56]. Figure S1 in the Supplemental Material (SM) section shows the results of three separate calibrations of small particle detection with miniSPLAT, following the procedure described in great detail in Vaden et al. [54]. It shows that while the precise $50 \%$ cut-off point of small
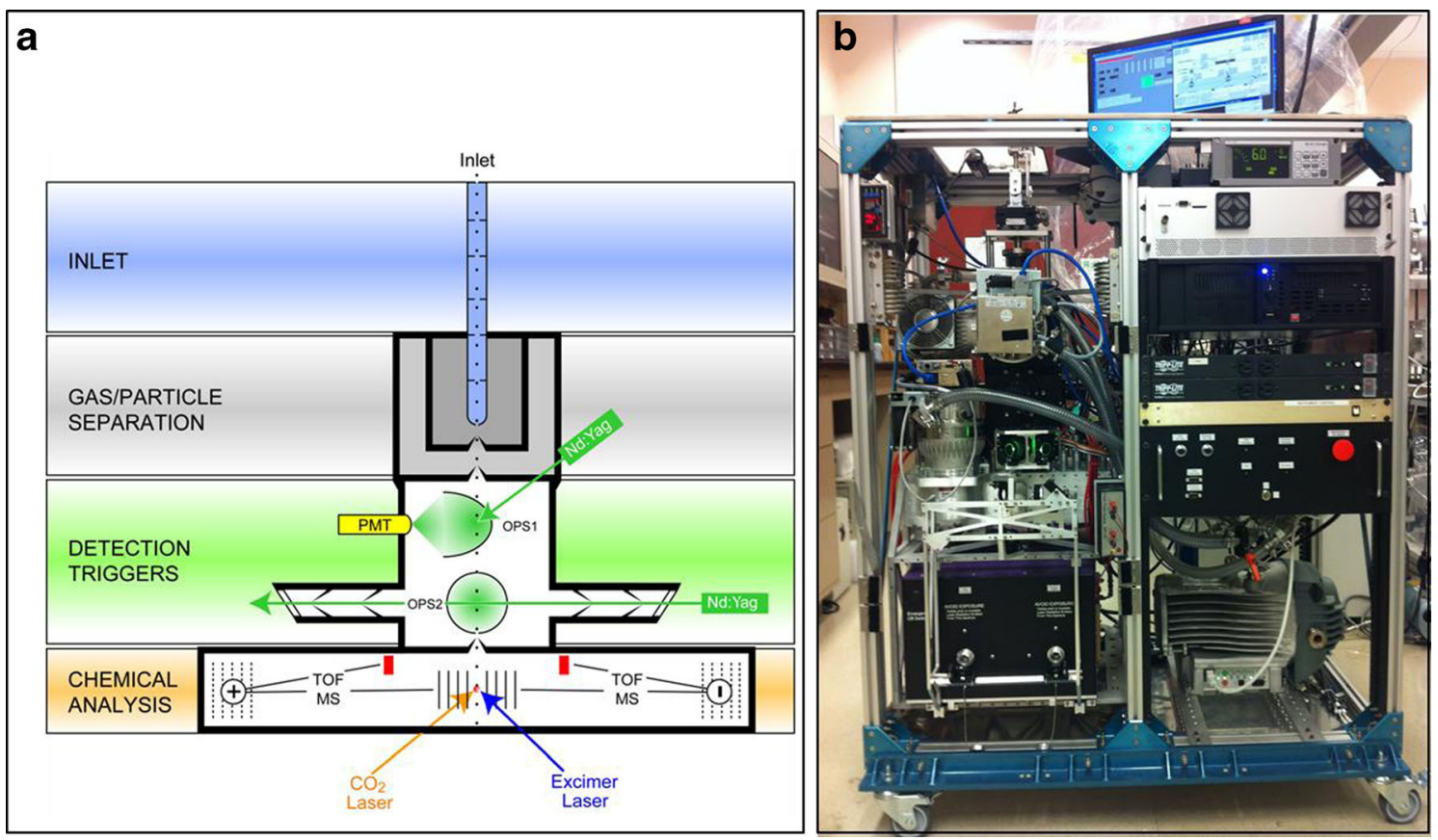

Figure 1. Schematics (a) and a photograph (b) of miniSPLAT. See text for details 
particle detection can vary, because of instrument alignment and the optics quality, between $79 \mathrm{~nm}$ and $83 \mathrm{~nm}(\sim 5 \%)$, it is nearly identical to that of SPLAT II $[11,54]$. It is also more than two orders of magnitude higher than the only other single particle mass spectrometer capable of detecting particles smaller than $100 \mathrm{~nm}[47,57]$.

This high sensitivity yields high temporal resolution, making it possible to size several thousand particles per s, while measuring the composition of up to 100 of them $[11,54,56]$. When the concentration of particles in the size range 100 to $600 \mathrm{~nm}$ is as low as 1 particles $\mathrm{cm}^{-3}$, miniSPLAT detects and characterizes at least one particle per s $[11,56]$.

When a particle triggers a detection event at both detection stages, its PTOF is used to generate, on the fly, size-dependent laser triggers to yield a size-independent hit-rate [55]. The laser is a custom-built dual-cavity laser (GAM Lasers Inc., Orlando, FL, USA) that produces two pulses: an infrared (IR) pulse used to evaporate semivolatile components in the particle, and an ultraviolet (UV) pulse used to ionize the evaporated plume and ablate the nonvolatile particle fraction $[11,55,58,59]$. The laser was designed and built specifically for miniSPLAT to fit the size limitations imposed by the aircraft rack and to minimize instrument weight.

The IR $\mathrm{CO}_{2}$ laser operates at $9.4 \mu \mathrm{m}$ with $20 \mathrm{~mJ} / \mathrm{pulse}$, and the UV excimer laser operates at $193 \mathrm{~nm}$ with $1.7-1.8 \mathrm{~mJ} /$ pulse. This is chosen because it is sufficient to ionize ammonium sulfate particles, while minimizing the fragmentation of organic molecules. Both lasers are focused to spots $\sim 0.5 \mathrm{~mm}$ diameter and aligned to ensure that each particle passes through the path of the $\mathrm{CO}_{2}$ laser beam first, before it reaches the timedelayed excimer laser beam path, as described in detail elsewhere $[11,58]$. This two-step ion formation approach yields, for semivolatile particles, mass spectra with reproducible fragmentation patterns and intensities proportional to particle mass [58]. The refractory components remain in the particle phase and are characterized with the same laser pulse by ablation $[11,53,58]$.

As shown in the photograph in Figure 1, the vacuum chamber, lasers, and optics are mounted to a second, internal frame in the left bay of the instrument rack that is suspended from the outside frame on a set of vibration isolation mounts. The electronics and a backing-pump are located in the right bay, away from the particle sampling and detection setup.

In miniSPLAT individual particle mass spectra are acquired using a dual-polarity Z-configuration reflectron time-of-flight (Z-TOF) mass spectrometer (Tofwerk AG, Thun, Switzerland) $[47,49]$. It consists of a single ion source region and two Vshaped flight paths (nominally $87 \mathrm{~cm}$ long), reflectors, and detectors (one for each ion polarity). Each detector is made up of a microchannel plate (MCP), scintillator, and PMT detector, and measures the time-dependent ion current. Ions have different flight times, separated according to their mass to charge ratio $(\mathrm{m} / \mathrm{z})$. The resulting signal is amplified by external amplifiers (ACA-2-13; Becker and Hickl GmbH, Berlin, Germany) [49] and digitized by a two-channel, 14-bit $\mathrm{A} / \mathrm{D}$ converter and stored. The mass spectrometer is equipped with optional delayed pulse extraction for improved mass-spectral resolution.
The custom-designed instrument control board and its associated software, identical to those used in SPLAT II [11], provide an intuitive graphical interface and real-time diagnostic readouts used to assure reproducible optimal instrument alignment, and to continuously monitor instrument operation. The board processes particle detection signals and generates triggers for the laser pulses and the A/D converter [11]. Particle number concentrations, sizes, and mass spectra are displayed in real-time, providing, on the fly, information about particle properties.

Figure 2 shows, as an example, the mass spectra of three individual particles characterized by miniSPLAT. The mass spectra of a $130 \mathrm{~nm}$ biomass burning particle (Figure 2a) and an aged $105 \mathrm{~nm}$ soot particle composed of a mixture of elemental carbon, oxygenated organics, and sulfate (Figure $2 b$ ) were acquired during miniSPLAT's first field deployment onboard the G-1 aircraft as part of the Two Column Aerosol Project (TCAP) field campaign. The positive and negative ion mass spectra of $200 \mathrm{~nm}$ sodium nitrate particle (Figure 2c and d, respectively) were obtained in the laboratory.

miniSPLAT and SPLAT II continuously operate in two simultaneous data acquisition modes: one characterizes the size and composition of individual particles at an operatordetermined rate of 20-100 particles/s; the second mode measures particle number concentration, asphericity, and $d_{v a}$ at a rate determined by the ambient particle number concentrations $[12,56]$. Number concentrations of particles larger than $100 \mathrm{~nm}$ are determined from the particle detection rate in the first optical stage with $1 \mathrm{~s}$ temporal resolution. Comparisons of particle number concentrations measured by the passive cavity aerosol spectrometer probe (PCASP) and SPLAT II show excellent agreement $[12,56]$. Particle asphericity is also measured with $1 \mathrm{~s}$ temporal resolution by calculating the ratio of the particle detection rates in the two optical detection stages [56]. This ratio is sensitive to particle beam divergence, which is affected by particle shape. For spherical particles larger than $100 \mathrm{~nm}$, the ratio is between 1 and 1.1, and for aspherical particles it increases to $2-4$, depending on particle shape. Particle $d_{v a}$ size distributions are calculated from the measured PTOF with a temporal resolution on the order of $\sim 60 \mathrm{~s}$, depending on particle concentration and the width of the size distributions. Particle $d_{v a}$ distributions are also used to calculate particle density [54]. This approach is particularly useful when applied to composition-resolved size distributions. These densities, together with the mass spectra, are used to obtain quantitative information on particle composition, determine relative amounts of different components in the internally mixed particles, and convert the vacuum aerodynamic diameters into particle geometric diameters $[54,60,61]$.

\section{Results and Discussion}

During the first phase of the TCAP campaign, miniSPLAT participated in all 10 research flights, sized $\sim 32$ million individual particles, and characterized the size and composition of 

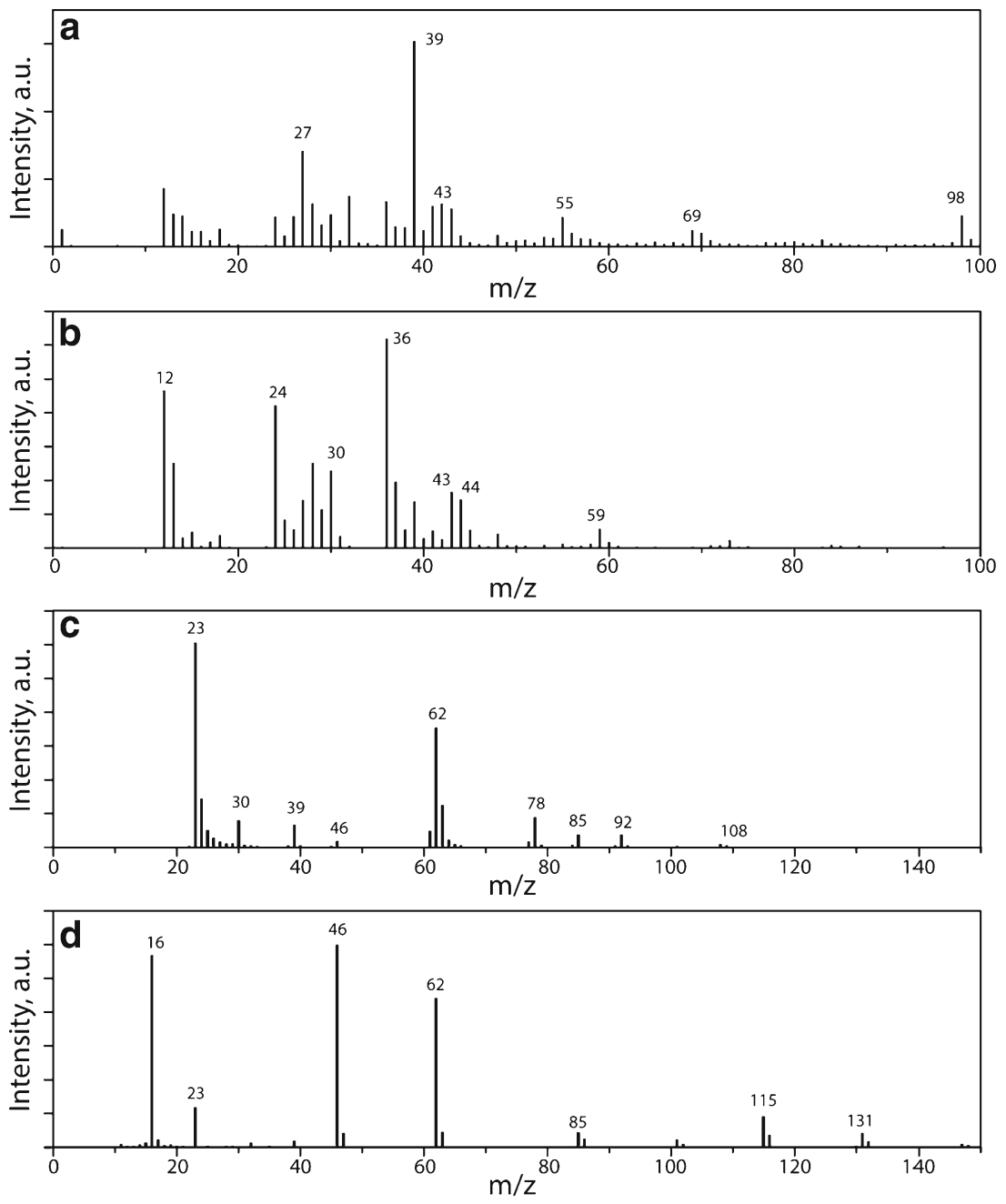

Figure 2. Mass spectra of three individual particles characterized by miniSPLAT: (a) a $130 \mathrm{~nm}$ biomass burning particle; (b) an aged $105 \mathrm{~nm}$ soot particle; (c) positive and (d) negative ion mass spectra of a $200 \mathrm{~nm}$ sodium nitrate particle

$\sim 250,000$ of them. A vast majority of the aerosol particles during TCAP were composed of oxygenated organics mixed with various amounts of sulfates. In addition, miniSPLAT characterized fresh and aged soot particles, biomass burning aerosol, organic amines, and a small number of dust and seasalt particles. Characteristic mass spectra of 14 particle classes characterized by miniSPLAT during this campaign are presented in Supplementary Figure S2. Supplementary Figure S3 provides the temporal evolution of the particle number concentrations and compositions as measured by miniSPLAT during the TCAP June 25th flight, plotted with $1 \mathrm{~s}$ and 2 min temporal resolutions, respectively. Supplementary Figure S3b shows that particle compositions varied only slightly with location, time, and altitude and would, therefore, not be a good example to use to illustrate the capabilities of ND-Scope.

In contrast, the data acquired by SPLAT II during ISDAC present diverse and interesting scenarios that include flight segments through very clean and highly polluted air masses, warm, mixed, and ice clouds. During a typical ISDAC flight, SPLAT II acquired the mass spectra of more than a 100,000 individual particles $[11,12]$. For example, during flight F26, which we present below, SPLAT II sized more than 7 million particles and measured the composition of $\sim 140,000$ particles, while collecting, in the second acquisition mode, particle number concentrations, size distributions, density, and asphericity, with 1-s resolution. This vast dataset needs to be analyzed in the context of data acquired by 41 other aerosol and cloud characterization instruments on board the aircraft [48].

Below, we illustrate the process of data organization/classification, visualization, and analysis of these large multidimensional datasets, using our newly developed interactive visual analytics framework, ND-Scope [35]. Moreover, to make use of this platform, it is essential to relate these data to the geospatial context.

Data analysis begins with classifying the individual particle mass spectra into a large number of distinct chemical classes that are hierarchically organized based on their mass spectral intensities using our SpectraMiner software [30]. The classified data are presented in a circular, interactive dendrogram that is visually intuitive and offers the researcher options to choose the level of detail suitable for each task. This allows us to explore the data at multiple levels, down to a single particle, and to 
ensure that any "golden nuggets," if present, are not lost. For the present analysis, classes with particles of similar composition were combined to yield 17 distinct classes. As an example, four types of sea salt particles (SS) that underwent atmospheric processing or aging to differing degrees were identified in the data and were combined here into a single class. Similarly, the organic particles, of which there were multiple types, were combined into four classes, whereas mineral dust and metallic particles were combined into a single class. Supplementary Figure $\mathrm{S} 4$ shows, as an example, mass spectra of 10 particle classes characterized by SPLAT II during ISDAC. Table 1 contains a legend of the compositions of different particle classes observed during F26 and the color code used later on to represent them in the pie charts and bar plots. In addition, the table lists the measured particle density, or effective density for each class, used to calculate its corresponding sulfate weight fraction [54]. The latter is an important quantity as it strongly affects particle interactions with ambient $\mathrm{RH}$, including hygroscopic growth and hence CCN activity.

We find that the majority of particles observed during F26 were $\mathrm{BB}$ and $\mathrm{BB}$ mixed with different amounts of sulfate. The observed BB plumes originating from forest fires and agricultural burning in southern Siberia [62-65] currently represent one of the most significant aerosol sources in the Arctic Spring that produce the "Arctic haze" and can significantly contribute to positive radiative forcing and snow-melt [63].

To examine the temporal evolution of particle composition, the data were binned into 1-min time intervals. Figure 3a shows

Table 1. A legend of the compositions of particle classes observed during F26, the colors used to represent them in Figures 3, 4 and 6, their measured particle densities, and sulfate weight fraction, measured with uncertainties of $\pm 5 \%$

\begin{tabular}{|c|c|c|c|}
\hline Color & Class & Density, $\mathrm{g}^{\circ} \mathrm{cm}^{-3}$ & Sulfate $W F, \%$ \\
\hline & BB & 1.32 & 0 \\
\hline & LowSulfBBorg & 1.35 & 15 \\
\hline & LowSulfBB & 1.38 & 15 \\
\hline & MedSulfBB & 1.47 & 40 \\
\hline & HighSulfBB & 1.58 & 60 \\
\hline & SulfBBorg & 1.45 & 40 \\
\hline & SootSulfBB & - & - \\
\hline & SulfLowOrg & 1.47 & 50 \\
\hline & SulfOrg & 1.30 & 20 \\
\hline & Org1 & 1.22 & 0 \\
\hline & Org2 & 1.24 & 0 \\
\hline & Org3 & 1.24 & 0 \\
\hline & Org4 & 1.24 & 0 \\
\hline & Pyridinium ion & 1.5 & 0 \\
\hline & Soot_org & 1.25 & 0 \\
\hline & SS & 1.5 & 0 \\
\hline & Mineral dust & - & - \\
\hline & & & \\
\hline & & & \\
\hline & & &
\end{tabular}

the corresponding temporal evolution of the flight altitude and aerosol number concentrations measured by SPLAT II $\left(N_{\text {splat }}\right)$. Figure $3 \mathrm{a}$ also shows time intervals when particles were sampled through an aerosol inlet (AI) and a counterflow virtual impactor (CVI) inlet, indicated in cream color. The AI is used to sample the overall clear sky aerosol population, particles above and below clouds, and, during in-cloud flight segments, provides information about interstitial particles [12]. The CVI inlet is used for in-cloud sampling to characterize cloud droplets and ice crystals residuals, as it is designed to transmit only large, super-micron particles [12]. Changes in the number concentrations of droplets $(N d)$ and ice crystals $(2 D P)$ as a function of time, illustrating sampling through clouds, are shown in Figure 3b. Figure 3c shows the number fraction of particles in each of the 17 chemical classes as a function of flight time, plotted in a bar plot presentation with 1-min resolution.

Figure 3a shows that during this flight, particle number concentrations varied from close to zero to over 2500 particles $\mathrm{cm}^{-3}$, and these changes occur relatively fast. Using aircraft altitude and time, we note that these data are indicative of the presence of horizontal and vertical filamentous layers, which is typical for a spring time Arctic atmosphere. Similarly, the data shown in Figure $3 \mathrm{c}$ indicate that particle composition vary significantly with time and altitude.

Thus far, we have displayed the composition data in a limited context, using conventional software, which does not relate the data to geographical location or make it possible to easily explore the relationship between the different observables. In the absence of additional tools, it is common to identify time intervals that might offer some interesting events and to proceed by extracting information about other observables for the same time periods $[12,48,64]$. Clearly, this laborintensive process is rather limited and, therefore, might or might not succeed.

To this end, we developed a new software package, NDScope, suitable for high-dimensional space exploration and specifically designed to address these challenges and make it possible to visually interact with multidimensional data, explore relationships among different variables, and interactively display their geo-spatial references.

ND-Scope relies on Google Earth (GE) with its intuitive options and controls to display and visualize the data in a geospatial context. Figure $4 \mathrm{a}$ is a screen capture of the ND-Scope GE view of the F26 flight track (red line), which started in Barrow, AK and ended in Fairbanks, AK. F26 began with a short transit over the Department of Energy Atmospheric Radiation Measurement (DOE ARM) ground site at Barrow, followed by $\sim 90$ minutes of sampling cloud at low-altitude, mostly over the ocean near Barrow. The aircraft then performed a spiral, climbing to an altitude of $\sim 7000 \mathrm{~m}$ and proceeding to land in Fairbanks. The time slider in the top left corner makes it possible to track and select different time intervals or locations. The white dots overlaid on the F26 track show the time interval markers for all aircraft data that were binned here with 1-min resolution. 

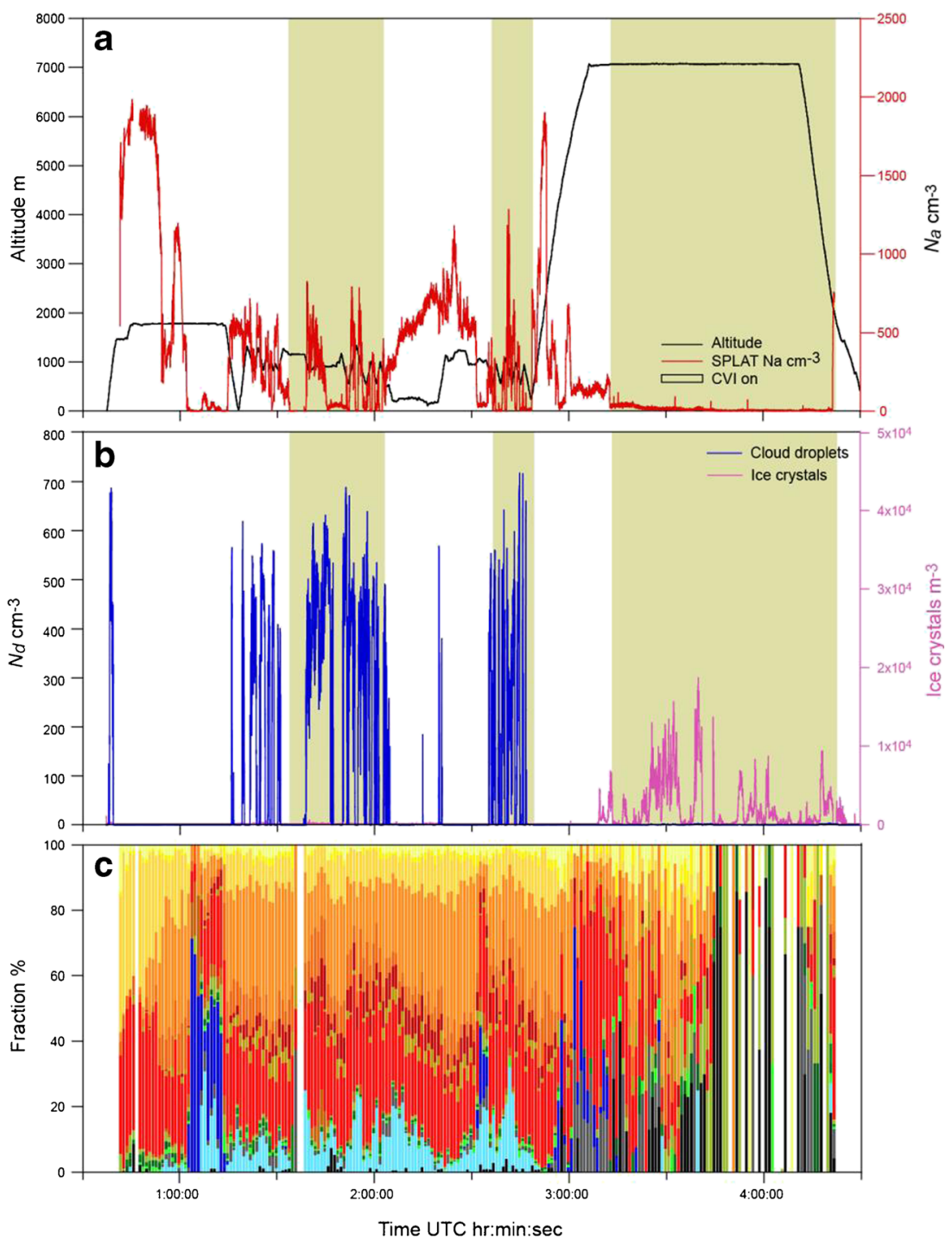

Figure 3. Data obtained on flight 26 of the ISDAC field campaign: (a) aircraft altitude (black) and particle number concentrations (red). The shaded light green areas indicate sampling through the CVI inlet; (b) cloud droplet number concentration (blue), and ice cloud crystals number concentrations (purple); (c) particle compositions, plotted as the fraction of number of particles, with 1-min resolution. See Table 1 for a composition legend

Clicking on a single dot displays a list of the values of all observables, including particle composition as the fraction of particles in each class, as demonstrated in Figure 4a with the first pie chart on the right (labeled 9). In addition, the program displays the particle composition in pie chart format, and the particle size distribution appears in the bottom left corner. All displayed data can be saved as a text file for future use.

The user can also select a number of points ("Select Area" Control), by marking the yellow polygon around them, as illustrated in Figure 4a. In this case, the program displays, in pie chart format (numbered 1 through 8 in the figure), particle compositions averaged over the enclosed segment. It also creates a corresponding data file listing all other observables along with their statistical analysis, providing averages, standard deviations, minima, and maxima.
This simple process of clicking the mouse to explore this complex and vast dataset offers an intuitive, fast, and easy to execute path to get a fast overview of the data. For example, a simple inspection of the data displayed in Figure $4 \mathrm{a}$ shows that particle composition changes significantly along the flight track. Close to Barrow, at lower altitudes (pie charts 1 and 2), particles containing BB and sea-salt dominate the aerosol population. During the entire high altitude segment, through thin ice-clouds (pie charts 3 through 8), a substantial fraction of the particles characterized by sampling through the CVI was dust, consistent with the idea that dust particles served as efficient IN. As the aircraft nears Fairbanks, particles are composed mostly of soot, dust, and organics, with only smaller contribution of BB-containing particles (pie chart 8). 

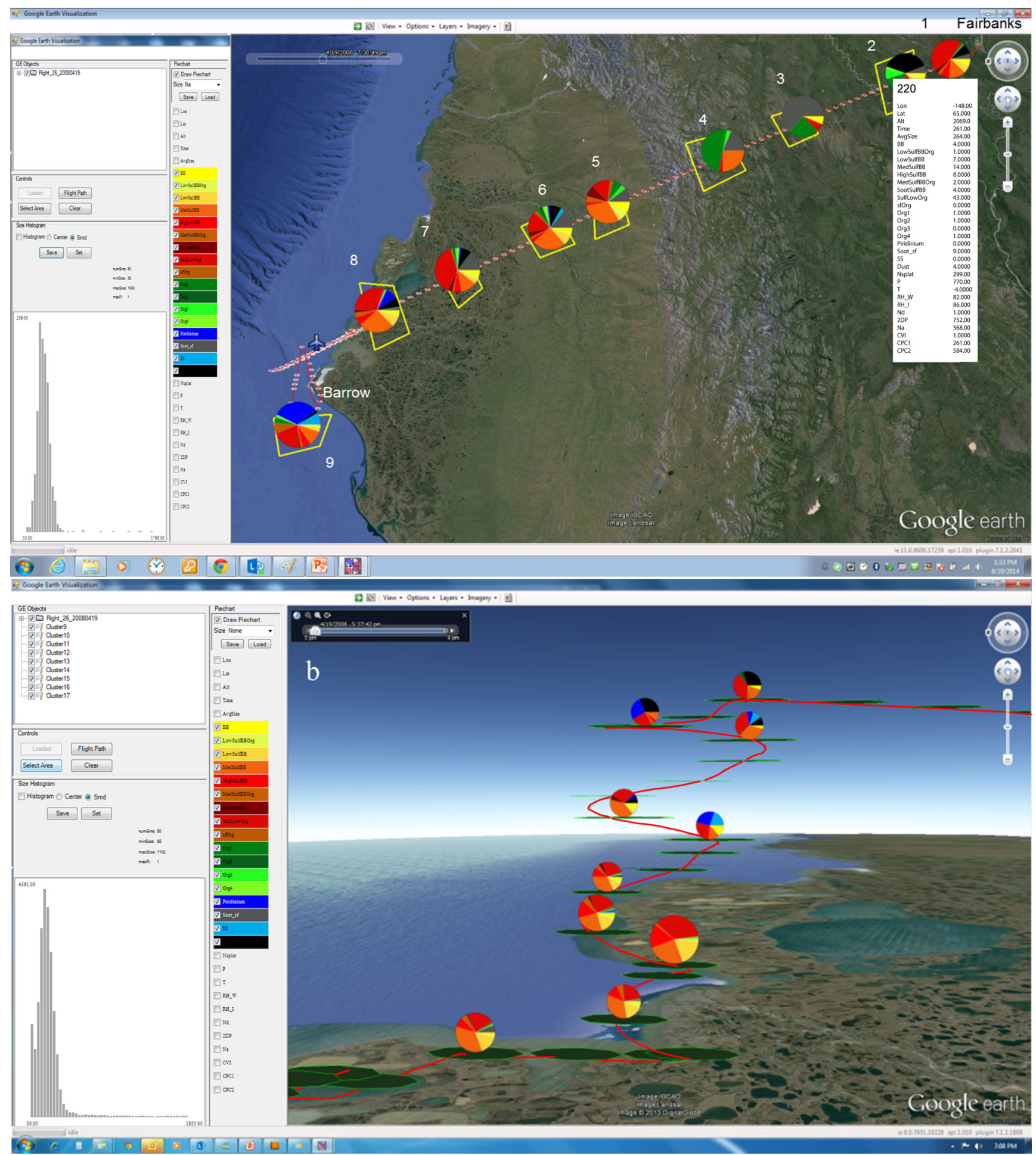

Figure 4. The Google Earth (GE) view of data collected during flight 26 of the ISDAC campaign: (a) white dots mark data points binned with 1-min resolution, overlaid on the flight track (red line). Pie charts show composition of particles characterized during a single 1-min interval (pie chart 9) and during time intervals enclosed in the yellow polygons; (b) zoom-in view of the ascending spiral that shows changes in particle compositions as a function of altitude. Here the pie chart diameters are proportional to particle number concentrations. See text for details

These observations of significant spatial variability in particle composition are consistent with previous reports of a highly stratified Arctic atmosphere [12, 61, 65].
Figure $4 \mathrm{~b}$ provides another illustration of the use of NDScope to visualize, in GE display, the data collected during a spiral. The aim in this case is to investigate aerosol properties as 
a function of altitude and so the user zoomed in on the spiral, during which the aircraft rapidly climbed from an altitude of a few $100 \mathrm{~m}$ to $7000 \mathrm{~m}$. The red line marks the aircraft trajectory, and the 1-min data points are indicated with the green circles. As before, clicking a dot displays particle compositions, size distributions, and a list of all other observables (not shown) that a second click on the page eliminates. A click on a subsequent dot generates the complete set of information, removes the list of the previous dot, but leaves the pie chart. The figure displays 10 pie charts, but without the corresponding lists. It is possible to use this display to convey information about an additional variable by scaling diameters of the pie charts to any of the other measured attributes, a list of which is available in the drop-down "Pie Chart" menu. In Figure 4b, the pie charts' diameters are proportional to particle number concentrations, $N_{\text {splat }}$, as measured by SPLAT.

A simple inspection of Figure $4 \mathrm{~b}$ shows that particle compositions changed significantly with altitude over the same location. Similarly, the pie chart diameters indicate that the most polluted aerosol layer was observed at mid-altitudes (1500-2000 m) and that this aerosol was comprised of BB and $\mathrm{BB}$ mixed with varying amount of sulfates particles.

Summarizing the information shown in Figure $4 a$ and b, we note that particle compositions and loadings varied significantly with changes in latitude, longitude, and altitude to produce a filamentous atmosphere that is very hard to encompass in a large scale climate model.

Using the diameter of the pie chart to display an additional observable represents a very limited approach to study the relationships between all observables. To this end, we have incorporated in ND-Scope a parallel coordinates (PC) view that is interactively coupled to the GE view.

Figure 5a shows the PC view of the 33 coordinates relevant to our present analysis of the F26 dataset. We included here: longitude, latitude, altitude, time, and average aerosol size, relative fraction of particles of different compositions, particle, droplet and ice crystal number concentrations, temperature, pressure, and RH. A vertical line that is named at the top, and marked with the minimum and maximum at the bottom and top, respectively, to define for each observable a scale, represents each coordinate. Coordinates can be removed, added, and reordered simply by dragging them out, in, or across the screen as required.

Each 1-min data point, labeled as a dot in the GE view (Figure 4), is shown here as a black line connecting the corresponding values of all observables displayed in the PC view. The GE and PC views are coupled: a click on a dot in the GE view highlights the corresponding line in the PC view. As an example, the line colored in red in Figure 5 marks the data point corresponding to dot/pie chart marked 1 in Figure 4a. Similarly, when a group of data points is selected by drawing a yellow polygon around dots in the GE view (Figure 4a), the corresponding lines in the PC view become highlighted.

ND-Scope also calculates and displays pairwise correlations and anti-correlations between all the attributes, as shown in
Figure $5 b$. Here, green and red lines represent correlations and anti-correlations, respectively, and the tunable opacity of these lines relates to the calculated $\mathrm{R}^{2}$. Some obvious relationships are easily observed: altitude is anti-correlated with temperature and pressure (red connecting lines), whereas temperature and pressure are correlated (green line). Similarly, particle number concentrations measured by four different instruments, with different size ranges [SPLAT II $\left(N_{\text {splat }}\right)$, PCASP $\left(N_{a}\right)$, and two condensation particle counters, (CPC1 and $\mathrm{CPC} 2)]$, are all correlated.

More informative and less intuitive information can also be extracted. Particle number concentrations are correlated with the fraction of LowSulfBB particles, composed of BB mixed with small amounts of sulfate (Table 1). This correlation illustrates the fact that highly polluted plumes were comprised mostly of $\mathrm{BB}$ and $\mathrm{BB} /$ sulfate mixtures, which, as we know, were transported from Asia. The figure also shows that average particle size (AvgSize) is correlated with altitude, thus anticorrelated with temperature and pressure. We will return to this point below.

We have already demonstrated that the user can change the PC display by selecting data points in the GE view. Similarly, the PC view provides a convenient way to filter/ select data to be viewed in GE. The "handles" (black arrows) at the top and bottom of each PC parameter can be dragged (the upper arrow down and/or the lower arrow up) to limit the display/analysis to data points that fit within the selected range. When arrows are dragged, the software displays the corresponding values.

Figure $5 \mathrm{c}$ shows a few examples of data selection for analysis using the PC view. First, by moving the bottom arrow of the $N_{\text {splat }}$ coordinate to 1000 particles $\mathrm{cm}^{-3}$, we select all highly polluted data points. The program displays the set of lines marked in orange and creates a data file containing information on these points with all corresponding observables. In addition, the user can group the lines into branches that can be "painted" and manipulated by adjusting settings like the standard deviation, opacity, spline tension, etc., which make it easier to follow the relationships between different attributes displayed as PC. For example, following the orange band in Figure $5 \mathrm{c}$, it can be seen that highly polluted plumes were observed over a narrow range of latitude and longitude, and only at mid-altitudes (1500 $2000 \mathrm{~m}$ ). It also shows that the majority of particles were composed of BB mixed with $15 \%$ sulfate (Table 1, LowSulfBB). We also note that these particles were detected at low RH and in clear sky (no droplets or ice crystals).

Selecting polluted data points in the PC view highlights them in the GE view because the PC and GE views are interactive and fully coupled. This is illustrated in Figure $5 \mathrm{~d}$ by the orange dots, showing that all but one of the highly polluted data points was characterized near Barrow, over the ocean.

Figure $5 \mathrm{c}$ also shows the data points that correspond to air masses with a high ( $>20 \%)$ fraction of dust particles (marked as the grey branch and lines), and those with more than $2 \%$ of particles being composed of sea-salt (marked as the turquoise 


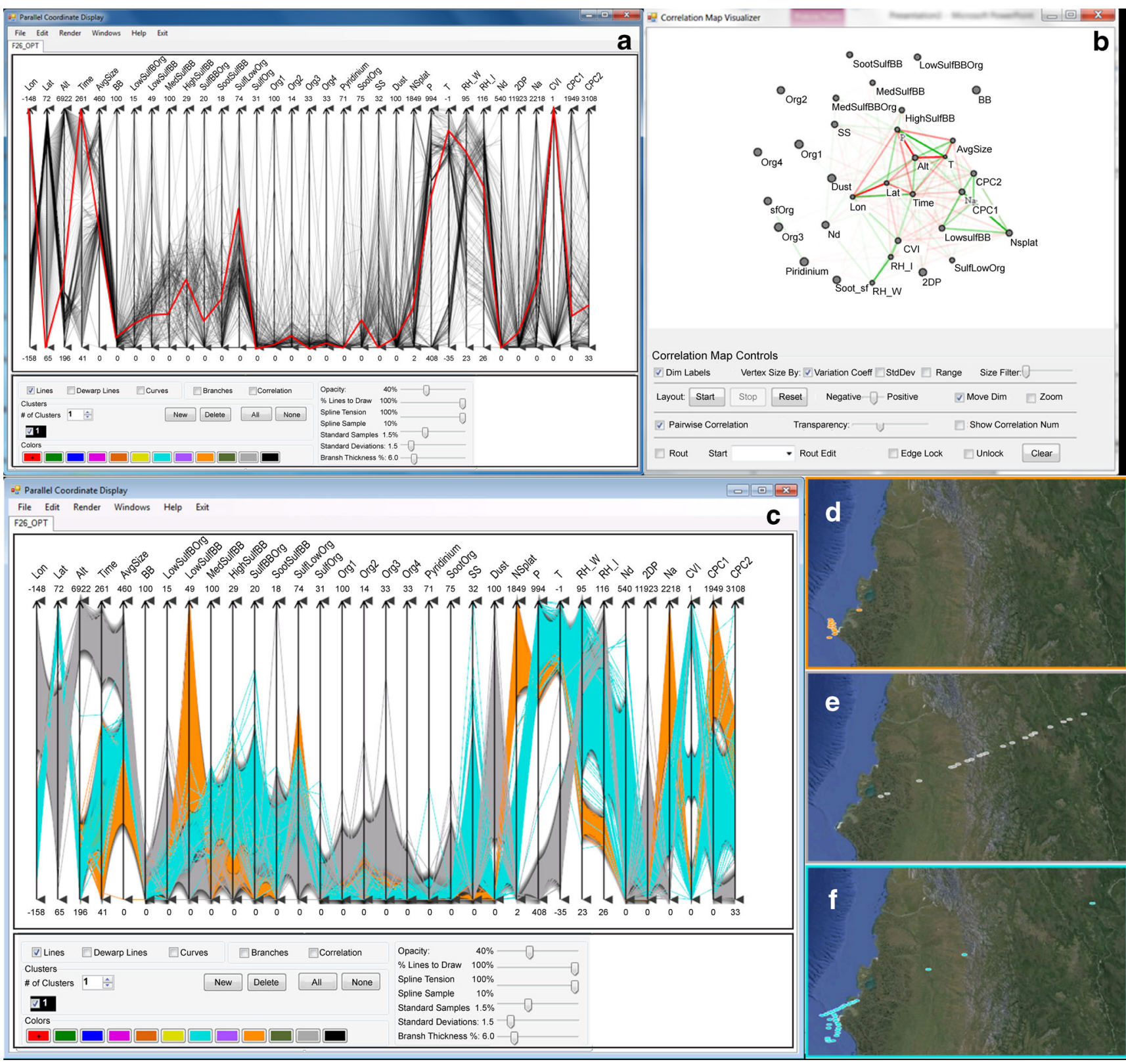

Figure 5. The Parallel Coordinates (PC) view of the data collected on flight 26 of the ISDAC campaign. (a) Each 1-min data point is shown here as a black line connecting the corresponding values of 33 PCs representing the values of 33 observables. The red line marks the values at data point marked 9 in Figure 4a; (b) Pairwise correlations (green) and anti-correlations (red) between all 33 observables; (c) the PC view of highly polluted data points (orange), and data points with a significant fraction of dust (grey) and seasalt particles (turquoise); (d)-(f) the corresponding GE view of highly polluted data points (orange), and data points with a significant fraction of dust (grey) and sea-salt particles (turquoise). See text for details

branch and lines). Each of these air masses was selected by moving up their respective bottom arrow.

Figure $5 \mathrm{c}$ shows that dust particles formed a large fraction of the aerosol at high altitudes (low temperatures and pressures) in the latter part of the flight, over a wide range of locations. This is illustrated in Figure 5e by the grey dots in the GE view. From the PC view, we learn that this flight segment was inside an ice cloud, as evident from the higher $2 D P$ values. This correlation between dust and ice crystals is consistent with experimental findings that dust particles serve as efficient ice nuclei. It also shows that the average size of particles in this segment was larger, explaining the correlation between aerosol average size and altitude observed in Figure $5 \mathrm{~b}$.

Air masses in which SS particles constitute more than 2\% of the particles are found at low-altitude (higher temperatures and pressures), in a narrow location range that is largely over the ocean, as evident from the corresponding GE view of the turquoise dots (Figure 5f). Moreover, the PC view shows that these data points are in a liquid cloud $\left(N_{d}>0\right)$. 
One of the main objectives of the ISDAC study was to investigate the relationship between particle properties and clouds. Below, we demonstrate how ND-Scope can be utilized to this end. As discussed above, during ISDAC the aircraft was equipped with two very different aerosol inlets - a CVI inlet and an AI. The CVI inlet rejects all un-activated/interstitial particles and transmits only cloud droplets, whereas the AI inlet lets only interstitial particles through, rejecting all cloud droplets. The PC labeled CVI offers a simple and direct method to choose between the two: by setting this coordinate to 1 , the user chooses to look at the properties of cloud residuals, and setting it to zero yields information on interstitial, un-activated particles.

We first select in-cloud flight segments only, by setting the number of cloud droplets to above background $\left(N_{d}>15\right.$ droplets $\mathrm{cm}^{-3}$ ) in the PC view. Then, by setting the $C V I$ value to 1 (or to
0 ), we select cloud residuals (interstitial particles) data to yield the blue (red) clusters in Figure 6a. For each of these settings, the program also yields a pie chart and marks the corresponding locations in the GE views shown in Figure $6 \mathrm{~b}$ and $\mathrm{c}$.

Comparing the red and blue clusters in the PC view, we note that aside from the CVI and time PCs, the biggest differences relate to particle composition: cloud droplet residuals appear to consist of larger fractions of more hygroscopic sea-salt particles and particles with higher sulfate content. Similar information is also conveyed by the corresponding pie charts shown in Figure $6 \mathrm{~b}$ and c. However, it is important to keep in mind that, as Figure $6 \mathrm{~b}$ and $\mathrm{c}$ show, the cloud residuals and interstitial particles were not sampled at the same location and time, and particle compositions can vary significantly with location, even in the vicinity of the same cloud.
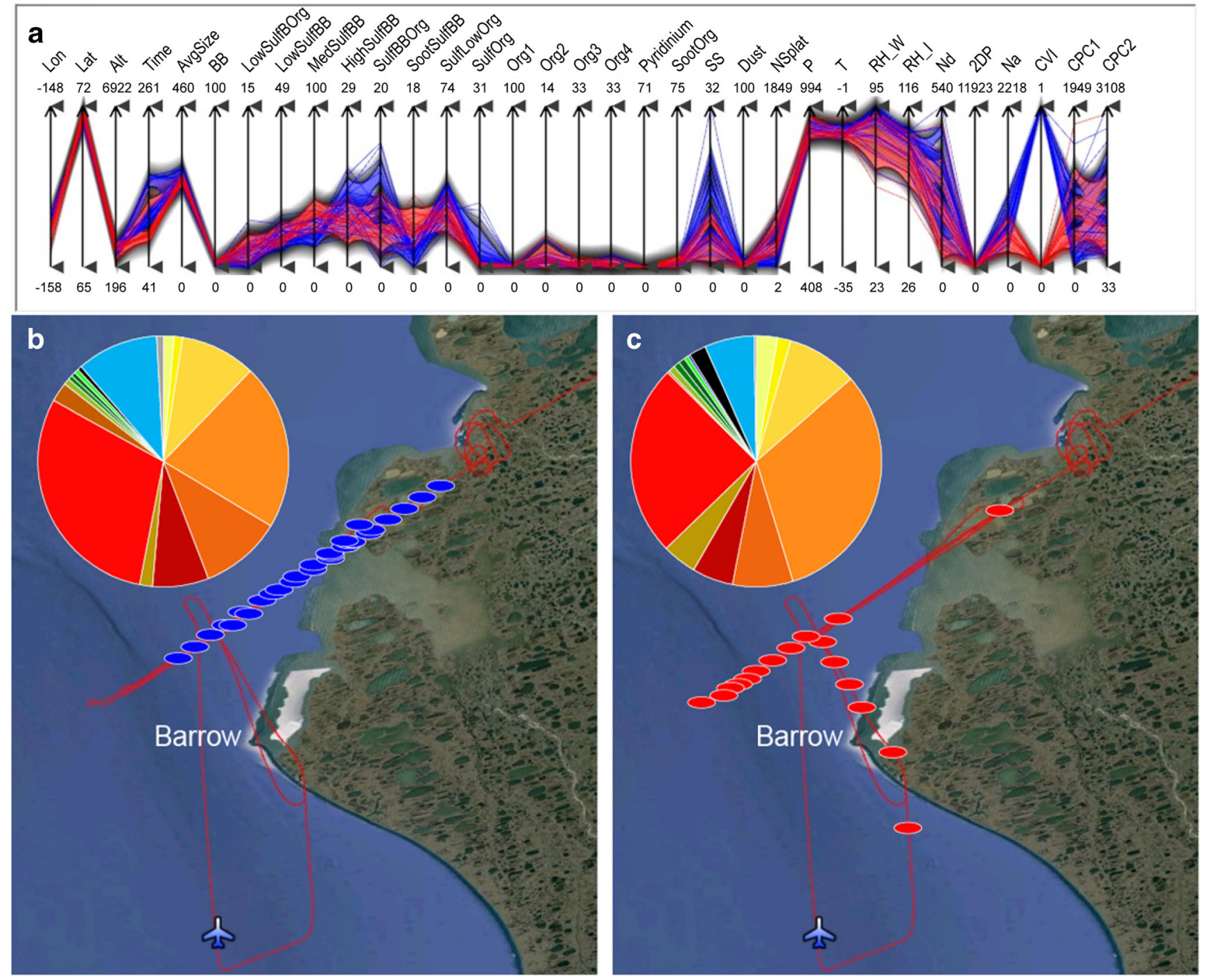

Figure 6. (a) The PC view of in-cloud sampling through the CVI inlet (blue) and Al (red) to provide information on cloud droplet residuals and interstitial particles, respectively; (b), (c) the GE view showing the locations where these measurements were conducted. The pie charts show compositions of cloud droplet residuals (b) and interstitial particles (c) 


\section{Conclusions}

Here we presented our aircraft-compatible single particle mass spectrometers, SPLAT II and miniSPLAT, used to characterize in-situ and in real-time the size and composition of individual aerosol particles with diameters from 50 to $2000 \mathrm{~nm}$. miniSPLAT operates on the same scientific principles as SPLAT II, which was described in detail in a number of publications, but has been significantly reduced in size, weight, and power consumption without loss in performance. Both instruments use photon counting for particle detection by light scattering, detecting $50 \%$ of 83 -nm-diameter particles, and $100 \%$ of spherical particles in the size range 125 to $600 \mathrm{~nm}$. The high detection efficiency and sensitivity of our SPMS makes it possible to size several 1000 particles per $\mathrm{s}$ with precision better than $0.5 \%$. Concurrently, they can record the composition of up to 100 particles per s. Our custom-designed instrument control board and its associated software used by both instruments provide an intuitive graphical interface for instrument alignment and operation. Size-dependent laser triggers are generated to eliminate size-dependent hit rate, a common problem with SPMS. The individual particle mass spectra are generated in a two-step process, using a $\mathrm{CO}_{2}$ laser pulse to evaporate the particle and a time-delayed excimer pulse to generate ions. This two-step IR/UV approach generates reproducible mass spectra with significantly reduced fragmentation and matrix effects compared with a single-step, laser ablation approach. Single particle mass spectra are acquired using a dual-polarity Z-configuration reflectron time-of-flight mass spectrometer in miniSPLAT and a single polarity angular reflectron time-of-flight mass spectrometer in SPLAT II. Both instruments continuously operate in dual data acquisition mode to measure, in addition to single particle size and composition, particle number concentrations, size distributions, density, and asphericity with high temporal resolution.

miniSPLAT and SPLAT II were successfully deployed during airborne field campaigns to characterize individual atmospheric aerosol particles. We find that properties of atmospheric particles, including number concentration and composition, change rapidly with location and altitude. We demonstrated that both instruments have the sensitivity, temporal resolution, precision, and quantitative capability to fulfill the stringent requirements of aircraft deployment.

We also presented our newly developed interactive visual analytics software package, ND-Scope, designed to explore and visualize the vast amount of data, acquired by our SPMS and other aerosol and cloud characterization instruments onboard the aircraft. We showed that ND-Scope makes it possible to visualize the relationships between observables and to view the data in a geo-spatial context, using the interactive GE display. In ND-Scope, the GE view is tightly linked to PC display, allowing the user to select the data points of interest based on their location or values of measured attributes.

We illustrated the utility of ND-Scope by applying it to visualize and analyze data obtained on one flight during the ISDAC field campaign. We showed how ND-Scope provides a simple path to explore the spatial distribution of particles with different compositions. ND-Scope was also used to explore the relationship between particle composition and $\mathrm{CCN}$ activity by comparing cloud droplet residuals with interstitial particles.

ND-Scope is a data visualization and analysis software package suitable for all complex, multidimensional data taken in a geo-spatial context and can be easily modified for different applications. A copy of the software can be obtained by contacting the corresponding author.

\section{Acknowledgments}

This work was supported by the US Department of Energy (DOE) Office of Basic Energy Sciences, Division of Chemical Sciences, Geosciences, and Biosciences (development of SPLAT II, miniSPLAT, and ND-Scope), the US DOE Office of Biological and Environmental Research (OBER), Atmospheric Radiation Measurement (ARM), Program Climate Research Facility, and Atmospheric Research Systems Program (ASR) (development of the aircraft deployment module and participation in ISDAC and TCAP field campaigns). Additional support was provided by the US National Science Foundation (ZZ \& KM, grant IIS-1117132). Klaus Mueller was partially supported by the MSIP (Ministry of Science, ICT and Future Planning), Korea, under the "IT Consilience Creative Program (ITCCP)" (NIPA-2013-H0203-13-1001) supervised by NIPA (National IT Industry Promotion Agency)Some of the data were obtained from the ARM program archive, sponsored by the DOE OBER Environmental Science Division. A portion of the research was performed using EMSL, a DOE Office of Science User Facility sponsored by the DOE OBER and located at Pacific Northwest National Laboratory.

The authors thank James Ewing, John Hubbe, the crews of Convair 580 and G-1 aircrafts, and the entire ISDAC and TCAP teams for their help in making miniSPLAT aircraft compatible and for their help during the field campaigns.

\section{References}

1. Shindell, D., Faluvegi, G.: Climate response to regional radiative forcing during the twentieth century. Nat. Geosci. 2, 294-300 (2009)

2. Intergovernmental Panel on Climate Change (IPCC) Climate Change 2007: The Physical Science Basis: Contribution of Working Group I to the Fourth Assessment Report of the IPCC. Cambridge University Press: Cambridge, UK (2007)

3. Albrecht, B.A.: Aerosols, cloud microphysics, and fractional cloudiness. Science 245, 1227-1230 (1989)

4. Liou, K.N., Ou, S.C.: The role of cloud microphysical processes in climate - an assessment from a one-dimensional perspective. J. Geophys. Res.-Atmos. 94, 8599-8607 (1989)

5. Twomey, S.: Pollution and planetary albedo. Atmos. Environ. 8, 12511256 (1974)

6. Pauli, P., Ari, A., Tuukka, P., Maija, K.K., Mikko, Ä., Heikki, J., Thomas, H., Jonathan, P.D.A., Almut, A., Wolfram, B., van der Hugo Denier, G., Amar, H., András, H., Lauri, L., Ari, L., Leaitch, W.R., Christian, P.-D., Sara, C.P., Petri, R., Erik, S., Alfred, W., Douglas, R.W., Veli-Matti, K., Markku, K.: Warming-induced increase in aerosol number concentration likely to moderate climate change. Nat. Geosci. 6, 438-442 (2013)

7. Forster, P., Ramaswamy, V., Artaxo, P., Berntsen, T., Betts, R., Fahey, D.W., Haywood, J., Lean, J., Lowe, D.C., Myhre, G., Nganga, J., Prinn, R., Raga, G., Schulz, M., Van Dorland, R.: Changes in 
atmosphericconstituents and in radiative forcing. In: Climate change 2007: The physical science basis. Contribution of working group I to the fourth assessment report of the intergovernmental panel on climate change. In: Solomon, S., Qin, D., Manning, M., Chen, Z., Marquis, M., Averyt, K.B., Tignor, M. and Miller, H.L. (eds.). Cambridge Univ Press: Cambridge, UK and New York, NY, USA (2007)

8. Lohmann, U.: A glaciation indirect aerosol effect caused by soot aerosols. Geophys. Res. Lett. 29(4), 1052 (2002)

9. McFiggans, G., Artaxo, P., Baltensperger, U., Coe, H., Facchini, M.C., Feingold, G., Fuzzi, S., Gysel, M., Laaksonen, A., Lohmann, U., Mentel, T.F., Murphy, D.M., O’Dowd, C.D., Snider, J.R., Weingartner, E.: The effect of physical and chemical aerosol properties on warm cloud droplet activation. Atmos. Chem. Phys. 6, 2593-2649 (2006)

10. Zelenyuk, A., Imre, D.: Beyond single particle mass spectrometry: multidimensional characterisation of individual aerosol particles. Int. Rev. Phys. Chem. 28, 309-358 (2009)

11. Zelenyuk, A., Yang, J., Choi, E., Imre, D.: SPLAT II: an aircraft compatible, ultra-sensitive, high precision instrument for in-situ characterization of the size and composition of fine and ultrafine particles. Aerosol Sci. Technol 43, 411-424 (2009)

12. Zelenyuk, A., Imre, D., Earle, M., Easter, R., Korolev, A., Leaitch, R., Liu, P., Macdonald, A.M., Ovchinnikov, M., Strapp, W.: In situ characterization of cloud condensation nuclei, interstitial, and background particles using the single particle mass spectrometer. SPLAT II. Anal. Chem. 82, 7943-7951 (2010)

13. Cantrell, W., Shaw, G., Cass, G.R., Chowdhury, Z., Hughes, L.S., Prather, K.A., Guazzotti, S.A., Coffee, K.R.: Closure between aerosol particles and cloud condensation nuclei at Kaashidhoo Climate Observatory. J. Geophys. Res.-Atmos. 106, 28711-28718 (2001)

14. Medina J., Nenes A., Sotiropoulou, R.E.P., Cottrell, L.D., Ziemba, L.D., Beckman, P.J., Griffin, R.J.: Cloud condensation nuclei closure during the International Consortium for Atmospheric Research on Transport and Transformation 2004 campaign: effects of size-resolved composition. J. Geophys. Res.-Atmos. 112, Artn D10s31 (2007)

15. Broekhuizen, K., Chang, R.Y.W., Leaitch, W.R., Li, S.M., Abbatt, J.P.D.: Closure between measured and modeled cloud condensation nuclei (CCN) using size-resolved aerosol compositions in downtown Toronto. Atmos. Chem. Phys. 6, 2513-2524 (2006)

16. Ervens B., Cubison, M., Andrews, E., Feingold, G., Ogren, J.A., Jimenez, J.L., DeCarlo, P., Nenes, A.: Prediction of cloud condensation nucleus number concentration using measurements of aerosol size distributions and composition and light scattering enhancement due to humidity. J. Geophys. Res.-Atmos. 112, Artn D10s32 (2007)

17. Lance S., Nenes, A., Mazzoleni, C., Dubey, M.K., Gates, H., Varutbangkul, V., Rissman, T.A., Murphy, S.M., Sorooshian, A., Flagan, R.C., Seinfeld, J.H., Feingold, G., Jonsson, H.H.: Cloud condensation nuclei activity, closure, and droplet growth kinetics of Houston aerosol during the Gulf of Mexico Atmospheric Composition and Climate Study (GoMACCS). J. Geophys. Res.-Atmos. 114, Artn D00f1 5 (2009)

18. Cubison, M.J., Ervens, B., Feingold, G., Docherty, K.S., Ulbrich, I.M., Shields, L., Prather, K., Hering, S., Jimenez, J.L.: The influence of chemical composition and mixing state of Los Angeles urban aerosol on CCN number and cloud properties. Atmos. Chem. Phys. 8, 5649-5667 (2008)

19. Dusek, U., Frank, G.P., Hildebrandt, L., Curtius, J., Schneider, J., Walter, S., Chand, D., Drewnick, F., Hings, S., Jung, D., Borrmann, S., Andreae, M.O.: Size matters more than chemistry for cloud-nucleating ability of aerosol particles. Science 312, 1375-1378 (2006)

20. Furutani, H., Dall .osto, M., Roberts, G.C., Prather, K.A.: Assessment of the relative importance of atmospheric aging on $\mathrm{CCN}$ activity derived from field observations. Atmos. Environ. 42, 3130-3142 (2008)

21. Quinn, P.K., Bates, T.S., Coffman, D.J., Covert, D.S.: Influence of particle size and chemistry on the cloud nucleating properties of aerosols. Atmos. Chem. Phys. 8, 1029-1042 (2008)

22. Murphy, D.M.: The design of single particle laser mass spectrometers. Mass Spectrom. Rev. 26, 150-165 (2007)

23. Pratt, K.A., Prather, K.A.: Mass spectrometry of atmospheric aerosolsu. Recent developments and applications. Part II: On-line mass spectrometry techniques. Mass Spectrom. Rev. 31, 17-48 (2012)

24. Thomson, D.S., Schein, M.E., Murphy, D.M.: Particle analysis by laser mass spectrometry WB-57F instrument overview. Aerosol. Sci. Technol. 33, 153-169 (2000)

25. Hinz, K.P., Greweling, M., Drews, F., Spengler, B.: Data processing in online laser mass spectrometry of inorganic, organic, or biological airborne particles. J. Am. Soc. Mass Spectrom. 10, 648-660 (1999)
26. Murphy, D.M., Middlebrook, A.M., Warshawsky, M.: Cluster analysis of data from the particle analysis by laser mass spectrometry (PALMS) instrument. Aerosol Sci. Technol. 37, 382-391 (2003)

27. Phares, D.J., Rhoads, K.P., Wexler, A.S., Kane, D.B., Johnston, M.V.: Application of the ART-2a algorithm to laser ablation aerosol mass spectrometry of particle standards. Anal. Chem. 73, 2338-2344 (2001)

28. Rebotier, T.P., Prather, K.A.: Aerosol time-of-flight mass spectrometry data analysis: a benchmark of clustering algorithms. Anal. Chim. Acta. 585, 38-54 (2007)

29. Song, X.H., Hopke, P.K., Fergenson, D.P., Prather, K.A.: Classification of single particles analyzed by ATOFMS using an artificial neural network, ART-2a. Anal. Chem. 71, 860-865 (1999)

30. Zelenyuk, A., Imre, D., Cai, Y., Mueller, K., Han, Y.P., Imrich, P.: SpectraMiner, an interactive data mining and visualization software for single particle mass spectroscopy: a laboratory test case. Int. J. Mass Spectrom. 258, 58-73 (2006)

31. Zelenyuk, A., Imre, D., Nam, E.J., Han, Y.P., Mueller, K.: ClusterSculptor: software for expert-steered classification of single particle mass spectra. Int. J. Mass Spectrom. 275, 1-10 (2008)

32. Ramakrishnan, R., Schauer, J.J., Chen, L., Huang, Z., Shafer, M.M., Gross, D.S., Musicant, D.R.: The EDAM project: mining atmospheric aerosol datasets. Int. J. Intell. Syst. 20, 759-787 (2005)

33. Engel, D., Hummel, M., Hoepel, F., Bein, K., Wexler, A., Garth, C., Hamann, B., Hagen, H.: Towards high-dimensional data analysis in air quality research. Comput. Graph. Forum 32, 101-110 (2013)

34. Hyunjung Lee J., McDonnell, K.T., Zelenyuk, A., Imre, D., Mueller, K.: A structure-based distance metric for high-dimensional space exploration with multi-dimensional scaling. Visualization and Computer Graphics, IEEE Transactions on , vol. 20, pp. 351-364, March 2014

35. Zhang, Z., Tong, X., McDonnell, K., Zelenyuk, A., Imre, D., Mueller, K.: Visual analytics with multi-field data: an application to climate research. Tsinghua Sci. Technol. 18, 111-124 (2012)

36. Nam, E.J., Han, Y., Mueller, K., Zelenyuk, A., Imre D.: ClusterSculptor: A visual analytics tool for high-dimensional data. Visual analytics science and technology, 2007. VAST 2007. IEEE Symposium on,pp.75-82, Oct. 30 2007-Nov. 12007

37. Gross, D.S., Atlas, R., Rzeszotarski, J., Turetsky, E., Christensen, J., Benzaid, S., Olson, J., Smith, T., Steinberg, L., Sulman, J., Ritz, A., Anderson, B., Nelson, C., Musicant, D.R., Chen, L., Snyder, D.C., Schauer, J.J.: Environmental chemistry through intelligent atmospheric data analysis. Environ. Model Softw. 25, 760-769 (2010)

38. Hinz, K.P., Spengler, B.: Instrumentation, data evaluation and quantification in on-line aerosol mass spectrometry. J. Mass Spectrom. 42, 843-860 (2007)

39. Nash, D.G., Baer, T., Johnston, M.V.: Aerosol mass spectrometry: an introductory review. Int. J. Mass Spectrom. 258, 2-12 (2006)

40. Noble, C.A., Prather, K.A.: Real-time single particle mass spectrometry: a historical review of a quarter century of the chemical analysis of aerosols. Mass Spectrom. Rev. 19, 248-274 (2000)

41. Sullivan, R.C., Prather, K.A.: Recent advances in our understanding of atmospheric chemistry and climate made possible by on-line aerosol analysis instrumentation. Anal. Chem. 77, 3861-3885 (2005)

42. McMurry, P.H.: A review of atmospheric aerosol measurements. Atmos. Environ. 34, 1959-1999 (2000)

43. Suess, D.T., Prather, K.A.: Mass spectrometry of aerosols. Chem. Rev. 99, 3007-3036 (1999)

44. Johnston, M.V.: Sampling and analysis of individual particles by aerosol mass spectrometry. J. Mass Spectrom. 35, 585-595 (2000)

45. Prather, K.A., Hatch, C.D., Grassian, V.H.: Analysis of atmospheric aerosols. Annu. Rev. Anal. Chem. 1, 485-514 (2008)

46. Laskin, A., Laskin, J., Nizkorodov, S.A.: Mass spectrometric approaches for chemical characterisation of atmospheric aerosols: critical review of the most recent advances. Environ. Chem. 9, 163-189 (2012)

47. Pratt, K.A., Mayer, J.E., Holecek, J.C., Moffet, R.C., Sanchez, R.O., Rebotier, T.P., Furutani, H., Gonin, M., Fuhrer, K., Su, Y.X., Guazzotti, S., Prather, K.A.: Development and characterization of an aircraft aerosol time-of-flight mass spectrometer. Anal. Chem. 81, 1792-1800 (2009)

48. McFarquhar, G.M., Ghan, S., Verlinde, J., Korolev, A., Strapp, J.W., Schmid, B., Tomlinson, J.M., Wolde, M., Brooks, S.D., Cziczo, D., Dubey, M.K., Fan, J.W., Flynn, C., Gultepe, I., Hubbe, J., Gilles, M.K., Laskin, A., Lawson, P., Leaitch, W.R., Liu, P., Liu, X.H., Lubin, D., Mazzoleni, C., Macdonald, A.M., Moffet, R.C., Morrison, H., Ovchinnikov, M., Shupe, M.D., Turner, D.D., Xie, S.C., Zelenyuk, A., Bae, K., Freer, M., Glen, A.: Indirect and semi-direct aerosol campaign the impact of arctic aerosols on clouds B. Am. Meteorol. Soc. 92, 183 (2011) 
49. Brands, M., Kamphus, M., Bottger, T., Schneider, J., Drewnick, F., Roth, A., Curtius, J., Voigt, C., Borbon, A., Beekmann, M., Bourdon, A., Perrin, T., Borrmann, S.: Characterization of a newly developed aircraft-based laser ablation aerosol mass spectrometer (ALABAMA) and first field deployment in urban pollution plumes over paris during MEGAPOLI 2009. Aerosol Sci. Technol. 45, 46-64 (2011)

50. Jayne, J.T., Leard, D.C., Zhang, X.F., Davidovits, P., Smith, K.A., Kolb, C.E., Worsnop, D.R.: Development of an aerosol mass spectrometer for size and composition analysis of submicron particles. Aerosol Sci. Technol. 33, 49-70 (2000)

51. Liu, P., Ziemann, P.J., Kittelson, D.B., Mcmurry, P.H.: Generating particle beams of controlled dimensions and divergence. 1. Theory of particle motion in aerodynamic lenses and nozzle expansions. Aerosol Sci. Technol. 22, 293-313 (1995)

52. Liu, P., Ziemann, P.J., Kittelson, D.B., Mcmurry, P.H.: Generating particle beams of controlled dimensions and divergence. 2. Experimental evaluation of particle motion in aerodynamic lenses and nozzle expansions. Aerosol Sci. Technol. 22, 314-324 (1995)

53. Zelenyuk, A., Imre, D.: Single particle laser ablation time-of-flight mass spectrometer: An introduction to SPLAT. Aerosol Sci. Technol. 39, 554-568 (2005)

54. Vaden, T.D., Imre, D., Beranek, J., Zelenyuk, A.: Extending the capabilities of single particle mass spectrometry. II. Measurements of Aerosol particle density without DMA. Aerosol Sci. Technol. 45, 125-135 (2011)

55. Zelenyuk, A., Yang, J., Imre, D., Choi, E.: Achieving size independent hit-rate in single particle mass spectrometry. Aerosol Sci. Technol. 43, 305-310 (2009)

56. Vaden, T.D., Imre, D., Beranek, J., Zelenyuk, A.: Extending the capabilities of single particle mass spectrometry. I. Measurements of aerosol number concentration, size distribution, and asphericity. Aerosol Sci. Technol. 45, 113-124 (2011)

57. Su, Y.X., Sipin, M.F., Furutani, H., Prather, K.A.: Development and characterization of an aerosol time-of-flight mass spectrometer with increased detection efficiency. Anal. Chem. 76, 712-719 (2004)
58. Zelenyuk, A., Yang, J., Imre, D.: Comparison between mass spectra of individual organic particles generated by UV laser ablation and in the IR/ UV two-step mode. Int. J. Mass. Spectrom. 282, 6-12 (2009)

59. Morrical, B.D., Fergenson, D.P., Prather, K.A.: Coupling two-step laser desorption/ionization with aerosol time-of-flight mass spectrometry for the analysis of individual organic particles. J. Am. Soc. Mass Spectrom. 9, 1068-1073 (1998)

60. Zelenyuk, A., Imre, D., Han, J.H., Oatis, S.: Simultaneous measurements of individual ambient particle size, composition, effective density, and hygroscopicity. Anal. Chem. 80, 1401-1407 (2008)

61. Earle M.E., Liu, P.S.K., Strapp, J.W., Zelenyuk, A., Imre, D., McFarquhar, G.M., Shantz, N.C., Leaitch, W.R.: Factors influencing the microphysics and radiative properties of liquid-dominated Arctic clouds: insight from observations of aerosol and clouds during ISDAC. J. Geophys. Res.Atmos. 116, Artn D00T09 (2011)

62. Warneke C., Bahreini, R., Brioude, J., Brock, C.A., de Gouw, J.A., Fahey, D.W., Froyd, K.D., Holloway, J.S., Middlebrook, A., Miller, L., Montzka, S., Murphy, D.M., Peischl, J., Ryerson, T.B., Schwarz, J.P., Spackman, J.R., Veres, P.: Biomass burning in Siberia and Kazakhstan as an important source for haze over the Alaskan Arctic in April 2008. Geophys. Res. Lett. 36, Artn L02813 (2009)

63. Warneke C., Froyd, K.D., Brioude, J., Bahreini, R., Brock, C.A., Cozic, J., de Gouw, J.A., Fahey, D.W., Ferrare, R., Holloway, J.S., Middlebrook, A.M., Miller, L., Montzka, S., Schwarz, J.P., Sodemann, H., Spackman, J.R., Stohl, A.: An important contribution to springtime Arctic aerosol from biomass burning in Russia. Geophys. Res. Lett. 37, Artn L01801 (2010)

64. Shantz, N.C., Gultepe, I., Andrews, E., Zelenyuk, A., Earle, M., Macdonald, A.M., Liu, P.S.K., Leaitch, R.: Optical, physical, and chemical properties of springtime aerosol over Barrow Alaska in 2008. Int. J. Climatol. 34, 3125-3138 (2014)

65. Shantz, N.C., Gultepe, I., Liu, P.S.K., Earle, M.E., Zelenyuk, A.: Spatial and temporal variability of aerosol particles in Arctic spring. Quart. J. Royal Meteorol. Soc. 138, 2229-2240 (2012) 